\section{Performance of RaCe Instrumentation System in Curved Root Canals: A Comprehensive Analysis by Three Study Methods}

\author{
Denise Piotto Leonardi ${ }^{1}$, Gilson Blitzkow Sydney ${ }^{2}$, Mário Tanomaru Filho ${ }^{3}$, \\ Flares Baratto-Filho ${ }^{1}$, Samantha Schaffer Pugsley Baratto ${ }^{1}$, Paulo Sérgio \\ Cerri $^{3}$
}

\author{
'Department of Dentistry, Positivo \\ University, Curitiba, PR, Brazil \\ ${ }^{2}$ Department of Dentistry, \\ UFPR - Federal University of \\ Paraná, Curitiba, PR, Brazil \\ ${ }^{3}$ Department of Dentistry, \\ UNESP - Univ Estadual Paulista, \\ UNESP, Araraquara, SP, Brazil
}

Correspondence: Profa. Dra. Denise Piotto Leonardi, Rua Prof. Pedro Viriato Parigot de Souza, 5300, 81280-330 Curitiba, PR, Brasil. Tel: +55-41-3317-3403. email: deleonardi@yahoo.com.br

\begin{abstract}
In this study, curved maxillary molar root canals were instrumented with RaCe rotary system to evaluate: 1 . the occurrence of canal transportation using a radiographic platform; 2 . the action of the instruments on the dentin walls, centering ability and canal enlargement by analysis of digital images; and the percentage of regular dentin surfaces and debris within the canal by histological analysis. Ten mesiobuccal roots of extracted human maxillary molars were embedded in acrylic resin and sectioned at the middle and apical thirds. Root canal shaping was performed using the RaCe rotary system at 250 $\mathrm{rpm}$ and $1 \mathrm{Ncm}$ torque. Each instrument set was used five times according to a crowndown technique in the following sequence: 40/0.10, 35/0.08, 25/0.06, 25/0.04, 25/0.02 (working length - WL), 30/0.02 (WL) and 35/0.02 (WL). Each instrument was inserted until resistance was felt and then pulled back, followed by brushing movements towards all canal walls. Each specimen was assessed by three study methods: radiographic platform, digitized image assessment and histological analysis. The radiographic platform showed lack of apical transportation. No statistically significant difference (Wilcoxon test, $p>0.05$ ) was found between the middle and apical thirds regarding instrument action on dentin walls, centering ability, area of root canal enlargement, percentage of regular dentin surfaces and debris within the root canal. It may be concluded that RaCe system is a suitable method for the preparation of curved root canals, regarding the maintenance of root canal original path, action on dentin walls, canal enlargement and removal of debris from the root canal lumen.
\end{abstract}

Key Words: nickel-titanium, rotary instruments, root canal preparation.

\section{Introduction}

Endodontic cleaning and shaping is challenging even for the most experienced professionals due to the variations in root canal anatomy. Root canal shaping influences the quality of the next steps of root canal irrigation and filling. Endodontic treatment of root canals with accentuated curvature can result in accidents, such as edge formation, perforation, canal transportation, zip formation and perforations, demanding longer clinical chairtime, patience and ability. These accidents make it difficult for clinicians to obtain a properly cleaned and filled root canal and might lead to endodontic treatment failure. Several authors have studied different endodontic techniques and instruments for cleaning and shaping (1-3), using different study methods: scanning electron microscopy (SEM) (1), preoperative and postoperative digital image superimposition (4), radiographic platform for assessing canal transportation; histological analysis for assessing the presence of predentin, action of instruments on canal walls, and debris in the root canal lumen $(5,6)$. These methods, however, have not enabled the comparison between pre- and post-preparation conditions. The Bramante technique (7) has been used for shaping assessment; it allows comparing root canal anatomy before and after instrumentation and this analysis is made by root canal images. Currently, micro-computed tomography (CT) scanning has been also employed, allowing root canal assessment before and after its preparation, without loss of dental structure. In the present study, root canals of maxillary molars were instrumented with a rotary system to evaluate: 1. the occurrence of canal transportation using a radiographic platform; 2 . the action of the instruments on the dentin walls, centering ability and canal enlargement by digital image assessment; and the percentage of regular dentin surfaces and debris within the canal by histological analysis.

\section{Material and Methods}

\section{Tooth and Root Canal Preparation}

This study was approved by the Ethics Committee of Positivo University (Process\# 103/2010). Ten mesiobuccal roots of extracted human maxillary molars were employed. On the buccal surface of each root, a longitudinal sulcus 
was prepared in order to facilitate the root canal walls identification in the histological analysis. Root canal length was determined by introducing a \#15 K-file (Dentsply Maillefer, Ballaigues, Switzerland) until its tip was visible at the apical foramen. Working length (WL) was established by subtracting $1 \mathrm{~mm}$ from the total length. Next, each specimen was positioned on a radiographic film and exposed to determine the curvature radius of each root. Only roots with curvature radius of $6 \mathrm{~mm}$ remained in the study. Next, the apical foramen of each root was sealed with silicone to prevent resin penetration into canals and embedded in clear self-curing polyester resin (Arazyn 11.0; Ara Quimica $\mathrm{S} / \mathrm{A}$, Araçariguama, SP, Brazil) in a rectangular shape block. Each resin block was taken to a precision cutting machine (Isomet Speed Saw; Buehler Ltd,. Lake Bluff, IL, USA) with a $0.15-\mathrm{mm}$-thick diamond disc and sectioned at the middle point of the root curvature (namely middle third) and $2 \mathrm{~mm}$ from the root apex (namely apical third). Each specimen was assessed by the three study methods.

\section{Radiographic Platform Assessment}

A platform was constructed in clear self-curing polyester resin according to the original root model. This new design enabled adapting the sectioned resin block with its segments juxtaposed in the correct position for the radiographic exposures. After the first radiographic exposure with a size 15 file (Dentsply Maillefer) inserted at the $\mathrm{WL}$, the root canal was prepared and a second radiographic exposure was made with a size 35 file (last instrument employed) inserted at WL. The same type of radiographic film (Kodak Insight; Eastman Kodak Company, Rochester, NY, USA) was used for both exposures.

\section{Digitized Image Assessment}

The middle and apical third segments were photographed with a digital camera and macro lens $100 \mathrm{~mm}$ (Pentax K 100 $D$; Haga-gun, Tochigi, Japan) using the same magnification and a camera/object distance standardized at $25 \mathrm{~cm}$. After root canal preparation, the segments were photographed again using the same standardization criteria of the preoperative images. Root canal shape was traced using CorelDraw X3 software (CoreIDRAW ${ }^{\circledR}$, Ottawa, ON, Canada), and new images were obtained. Pre- and postoperative outlined root canal area was measured by ImageTool 3.0 software (UTHSCSA, San Antonio, TX, USA) to determine the amount root canal enlargement. Measurements of root thickness were also obtained to verify whether canal preparation was centered. Superposition of preand postoperative contours was performed to evaluate instrument action on root canal walls; superposition was assessed by a pre-established 5-point scoring system: 0 : lack of instrument action on the dentin walls; 1 : instrument action on one dentin wall; 2: instrument action on two dentin walls; 3 : instrument action on three dentin walls; 4: instrument action on 4 dentin walls.

\section{Root Canal Preparation Technique}

Root canal shaping was performed with RaCe system (FKG Dentaire S.A. La Chaux-de-Fonds, Neuchâtel, Switzerland). An X-Smart (Dentsply Maillefer) electric motor was used with rotation speed adjusted to $250 \mathrm{rpm}$ and $1 \mathrm{Ncm}$ torque. Irrigation was performed with distilled water at every instrument change, totalizing $35 \mathrm{~mL}$.

Each instrument set was used five times according to a crown-down technique in the following sequence: 40/0.10, 35/0.08, 25/0.06, 25/0.04, 25/0.02 (WL), 30/0.02 $(\mathrm{WL})$ and 35/0.02 (WL). Each instrument was inserted until resistance was felt and then pulled back, followed by brushing movements towards all canal walls.

\section{Histological Analysis}

Each middle and apical third segment was immersed in $10 \%$ formaldehyde for $48 \mathrm{~h}$ until the histological processing started. Serial $6-\mu \mathrm{m}$-thick cross-sections were obtained with a microtome (Spencer model 820, Derry, NH, USA) and stainless steel razors (Leica, model 818, Wetzlar, Hesse, Germany). Approximately 100 sections were obtained from each root segment (middle and apical thirds), stained with hematoxylin and eosin (HE) and examined with light microscope (Model BX-51, Olympus, Tokyo, Japan). Root canal images from 5 non-serial sections of middle and apical thirds with an interval of about $100 \mu \mathrm{m}$ among them were captured by a digital camera coupled to the light microscope at 10x magnification. The percentage of regular surfaces was evaluated using ImageTool 3.0 software and the root canal perimeter was delimited in millimeters. Next, an arch was drawn on the irregular dentin surfaces to delimit the areas with less instrument action. Therefore, the arch length indicated, in millimeters, the root canal irregular surface. From the obtained data, the percentage of regular and irregular surfaces was calculated.

For calculating the percentage of debris in the canals, a crosshatching grid was constructed digitally, containing 228 quadrants, which was superimposed on each digital image. Using the ImageTool 3.0 software, the quadrants superimposed onto root canal area were counted using the software's "tag and count" tool. Next, the quadrants superimposed onto the debris within the root canal lumen were counted, which determined the percentage of the debris and, therefore, the cleaning ability of the rotary instruments.

\section{Statistical Analysis}

The Wilcoxon test was used for comparison between 
two groups and Friedman's test was used for comparison between more than two groups, considering the paired experimental data. Level of significance was set at $5 \%$ for all tests. These tests are based on signed ranks, but the description of results was performed by the mean value (a measure of results distribution) and minimum and maximum values (for establishing the dispersion around the mean value).

\section{Results}

\section{Radiographic Platform}

It was observed that both instruments were superimposed at the apical third and it was not possible to distinguish their tips. Consequently, angular variation was zero, which means lack of canal transportation.

\section{Digitized Image Assessment}

Instrument Action on Dentin Walls. In the middle third all specimens were scored 4, i.e., action on 4 dentin walls, while in the apical third 7 specimens received the same score. Although the action of the instruments in the apical third was not as uniform as in the middle third, no

Table 1. Descriptive statistical analysis of the percentage of root canal displacement towards the dentin walls after preparation of the root canals in each third

\begin{tabular}{|c|c|c|c|c|c|c|c|c|}
\hline \multirow{2}{*}{ Percent value } & \multicolumn{2}{|c|}{ Inner wall } & \multicolumn{2}{|c|}{ Outer wall } & \multicolumn{2}{|c|}{ Palatal wall } & \multicolumn{2}{|c|}{ Buccal wall } \\
\hline & MT & AT & MT & AT & MT & AT & MT & AT \\
\hline Minimum & 5.2 & 4.0 & 10.9 & 7.8 & 0.8 & 3.3 & 3.3 & 1.9 \\
\hline Maximum & 13.7 & 18.9 & 21.3 & 28.9 & 14.6 & 10.9 & 7.8 & 11.8 \\
\hline Mean & 8.2 & 8.4 & 15.5 & 18.7 & 4.1 & 6.5 & 5.9 & 6.4 \\
\hline Wilcoxon (p) & \multicolumn{2}{|c|}{$0.959^{*}$} & \multicolumn{2}{|c|}{$0.074^{*}$} & \multicolumn{2}{|c|}{$0.074^{*}$} & \multicolumn{2}{|c|}{$0.721^{*}$} \\
\hline
\end{tabular}

MT: middle third. AT: apical third. * not significant at 5\% level

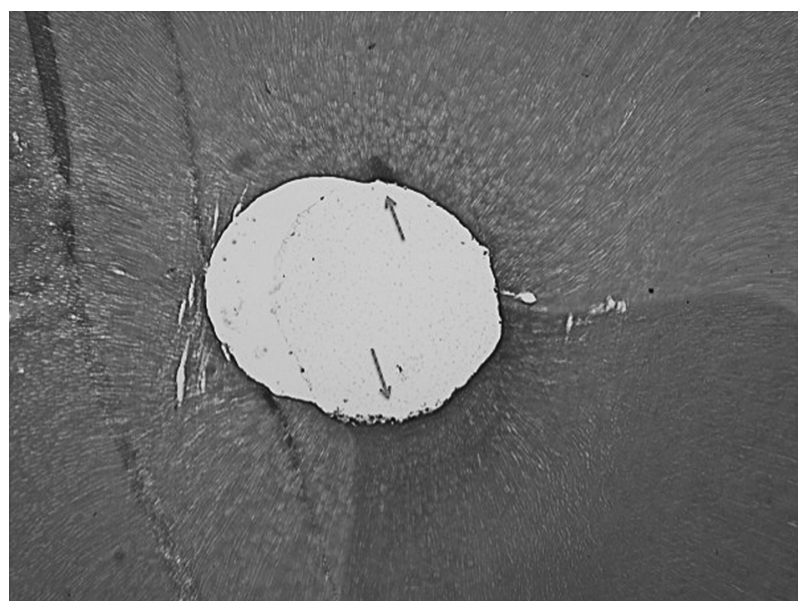

Figure 1. Apical third with non-instrumented dentin surface (arrows) (H.E., original magnification $10 \times$ ). statistically significant difference was found between the thirds ( $p=0.109$ ).

Centering Ability. Table 1 presents the descriptive statistical analysis of the percentage of root canal displacement towards the dentin walls after preparation. There were no significant differences of percentage between middle and apical thirds on any of the walls ( $p>0.05$ ). Additionally, there was no significant difference of percentage among the four walls $(p=0.109)$. The thickness of root canal dentin walls at the buccal, palatal, inner and outer areas of the curvature revealed greater dentin removal at the buccal and outer area of the curvature in the middle and apical thirds.

Area of Root Canal Enlargement. Wilcoxon test did not show any statistic difference between the percentage increase of area due to middle and apical third preparation ( $p=0.445$, not significant at $5 \%$ level).

\section{Histological Assessment}

There was no statistically significant difference between the middle and apical thirds regarding the percentage of root canal regular surfaces $(p=0.173)$ and regarding the presence of debris within the root canal (Figs. 1 and 2) ( $p=0.074)$.

\section{Discussion}

Regarding the root canal preparation phase, RaCe system has been evaluated with respect to its cleaning $(8)$ and shaping $(9,10)$ ability. Ten roots were used in the present study, which is a representative number since the same specimens were evaluated by three study methods. The roots were selected according to their curvature radius, which was essential for determining the
Figure 2. Middle third with presence of debris (asterisks) and noninstrumented dentin surface (arrows) (H.E., original magnification 10x). 
root canal curvature (11)

The radiographic platform method did not find canal transportation in any evaluated specimen. These results agree with those of Javaheri and Javaheri (12), who also found absence of transportation in mesiobuccal canals. Yoshimine et al. (10) using simulated canals, also achieved similar results. Comparing Protaper, K3, and RaCe instruments, Yoshimine et al. (10) observed a smaller transportation for RaCe and K3 systems. In addition, in the present study was observed that all specimens that did not show transportation in the radiograph, also did not present data that pointed to transportation, in the analysis of digitized image method, for example, excessive wearing at one dentinal wall.

The radiographs show a mesial-distal image, while the transversal observation of the root canal enables to assess the instrument action on all dentin walls (7), including the flattened areas. The descriptive analysis revealed that, in the middle third, especially on the outer wall, a greater number of prepared walls was observed in comparison with the apical third, although the statistical analysis did not find any significant difference between the two thirds' results. Also, by the digitized image method, in the mesialdistal direction of middle and apical third, the outer wall wear was always greater than on the inner wall. There is a relationship between the obtained descriptive data and the results from Aydin et al. (9), who observed greater dentin removal on the outer wall of the curvature in the apical third of simulated canals. Although the methodologies are different, similar results were found. While in the present study wear was seen transversally, and extracted teeth were used, Aydin et al. (9) performed an analysis in the longitudinal direction of the root canal and used simulated canals.

In the present study, the effects of instruments were examined $1.0 \mathrm{~mm}$ below the apex and in the middle of the curvature. By the descriptive analysis in both areas there was a greater wearing on the curvature's outer wall. In the buccal-palatal direction, was observed a greater root canal displacement towards the buccal wall, both at apical and middle thirds. These results agree with those of Limongi et al. (13), in which computed tomography was employed as a preparation assessment method in lower incisors prepared by RaCe rotary instruments.

Obviously, the greatest root canal enlargement at middle third is because RaCe instruments presented in this area a greater diameter according to their different tapers. Uyanik et al. (14) verified a general root canal enlargement of $37 \%$ when prepared by RaCe system. In this study, although the statistical test did not show any statistic difference between the percentage increase of area due to middle and apical third preparation, was found that
RaCe system provided a smaller root canal enlargement in apical third when compared to the middle third. This increase was proportional to the original root canal area. Therefore, it may be said that RaCe system maintained the original canal path. Previous studies emphasized that about $35 \%$ (or more) of root canal surface is not prepared, even when a NiTi rotary system is used (15). Greca et al. (16) evaluated different preparation techniques and observed than none was efficient regarding the action on root canal dentin walls. In the study of Zand et al. (8), RaCe system also did not reach all areas and remove debris from all root canal regions. The presence of unprepared areas may be explained by the anatomic features of root canal, such as mesial-distal root flatness. Langeland et al. (17) stated that root canal configuration plays a role as valuable as the employed technique.

Several studies $(8,18)$ evaluated the cleaning ability of RaCe rotary system. Even with the continuous and expansive development of instruments and preparation techniques, scientific literature has reported that there is not a single technique nor instrument system that totally cleans the root canal (5). Accordingly, this has been shown to occur mainly in the apical third area, which is considered the most difficult area to clean due to its anatomical complexity and difficult access (5).

Histological assessment is commonly employed for evaluating the cleaning and shaping ability $(5,18)$. Notwithstanding, there are recent methodologies employed for the same purpose. For example, the micro-CT scanning which produces data comparable to those obtained by histologic sectioning (19).

It is important to note that, in this study, root canal cleaning in the apical third was smaller than in the middle third, although the statistical test did not show any significant difference between them. These data agree with the scores obtained by the instruments' action on root canal walls. This fact suggests that if the apical third had been prepared by larger diameter instruments, a better cleaning would have been obtained.

On the other hand, if sodium hypochlorite had been employed as endodontic irrigant, a smaller amount of debris could have been found. But distilled water was intentionally used in order to isolate the cleaning ability of RaCe system, without the interference of the chemical action of endodontic irrigants, as shown by Barbizam et al. (5).

Contrary to what is expected, root canal cleaning is not exclusively dependent on endodontic preparation, even in round canals. Therefore, this clearly confirms that endodontic preparation by itself does not solve the cleaning issue. It is necessary to associate both appropriate instruments and biomechanical preparation techniques 
with irrigant solutions showing advantageous properties, in relation to their ability to remove organic and inorganic debris out of the root canal.

Considering the patterns followed by this study, it may be concluded that the RaCe system is a suitable method for curved root canals, regarding the maintenance of root canal original paths, action on dentin walls, area enlargement and removal of debris from the root canal lumen.

\section{Resumo}

0 objetivo do presente estudo foi verificar a presença de desvio apical por meio da plataforma radiográfica, avaliar a ação dos instrumentos, centralização do preparo e ampliação por meio de imagens digitais do canal e calcular a porcentagem de superficies regulares e presença de debris por meio da análise histológica. Dez raizes mésiovestibulares de molares superiores extraídos foram incluidos em blocos de resina e seccionados no terço médio e apical. 0 preparo do canal foi feito empregando o sistema RaCe, a $250 \mathrm{rpm}$ e torque de $1 \mathrm{Ncm}$. Cada sistema rotatório foi usado 5 vezes no sentido coroa-ápice na seguinte sequência: 40/0.10, 35/0.08, 25/0.06, 25/0.04, 25/0.02 (comprimento de trabalho - CT), 30/0/02 (CT) e 35/0/02 (CT). Cada amostra foi avaliada por 3 métodos de estudo: plataforma radiográfica, imagem digital e análise histológica. A plataforma radiográfica mostrou ausência de transporte apical. Em relação à ação dos instrumentos sobre as paredes dentinárias, centralização do preparo, ampliação, porcentagem de superfícies regulares e presença de debris, 0 teste estatístico de Wilcoxon não mostrou diferença significativa entre os terços apical e médio. 0 sistema RaCe se mostrou adequado para 0 preparo de canais radiculares curvos em relação à manutenção do trajeto original do canal, ação sobre as paredes dentinárias, ampliação e remoção de debris da luz do canal radicular.

\section{References}

1. Garip Y, Sazak H, Gunday M, Hatipoglu S. Evaluation of smear layer removal after use of a canal brush: an SEM study. Oral Surg Oral Med Oral Pathol Oral Radiol Endod 2010;110:e62-e66.

2. de Melo Ribeiro MV, Silva-Sousa YT, Versiani MA, Lamira A, Steier L, Pécora JD, et al.. Comparison of the cleaning efficacy of self-adjusting file and rotary systems in the apical third of oval-shaped canals. J Endod 2013;39:398-401.

3. Lim YJ, Park SJ, Kim HC, Min KS. Comparison of the centering ability of Wave.One and Reciproc nickel-titanium instruments in simulated curved canals. Restor Dent Endod 2013;38:21-25.

4. Garala M, Kuttler S, Hardigan P, Steiner-Carmi R, Dorn S. A comparison of the minimum canal wall thickness remaining following preparation using two nickel-titanium rotary systems. Int Endod J 2003;36:636-
642.

5. Barbizam JVB, Fariniuk LF, Marchesan MA, Pecora JD, Souza-Neto MD. Effectiveness of manual and rotary instrumentation techniques for cleaning flattened root canals. J Endod 2002;28:365-366.

6. da Frota MF, Filho IB, Berbert FL, Sponchiado EC Jr, Marques AA, Garcia $L$ da F. Cleaning capacity promoted by motor-driven or manual instrumentation using ProTaper Universal system: Histological analysis. J Conserv Dent 2013;16:79-82.

7. Bramante $C M$, Berbert $A$, Borges RP. A methodology for evaluation of root canal instrumentation. J Endod 1987;13:243-245.

8. Zand V, Bidar M, Ghaziani P, Rahimi S, Shahi S. A comparative SEM investigation of the smear layer following preparation of root canals using nickel titanium rotary and hand instruments. J Oral Sci 2007;49:47-52.

9. Aydin C, Inan U, Yasar S, Bulucu B, Tunca Y. Comparison of shaping ability of RaCe and Hero Shaper instruments in simulated curved canal. Oral Surg Oral Med Oral Pathol Oral Radiol Endod 2008;105:e92-e97.

10. Yoshimine $Y$, Ono $M$, Akamine A. The shaping effects of three nickeltitanium rotary instruments in simulated S-shaped canals. J Endod 2005:31:373-375

11. Riitano F. Anatomic Endodontic Technology (AET) - a crown-down root canal preparation technique: basic concepts, operative procedure and instruments. Int Endod J 2005;38:575-587.

12. Javaheri $\mathrm{HH}$, Javaheri $\mathrm{GH}$. A comparison of three NiTi rotary instruments in apical transportation. J Endod 2007;33:284-286

13. Limongi 0 , Albuquerque DS, Baratto-Filho F, Vanni JR, Oliveira EM, Barletta FB. In vitro comparative study of manual and mechanical rotary instrumentation of root canals using computed tomography. Braz Dent J 2007;18:289-293.

14. Uyanik MO, Cebreli ZC, Mocan BO, Dagli F. Comparative evaluation of three nickel-titanium instrumentation systems in human teeth using computed tomography. J Endod 2006;32:668-671.

15. Peters $\mathrm{AO}$, Schöenenberger $\mathrm{K}$, Laib A. Effect of four Ni-Ti preparation techniques on root canal geometry assessed by microcomputer tomography. Int Endod J 2001;34:221-230.

16. Grecca FS, Garcia RB, Bramante, CM, Moraes IG, Bernardineli N. A quantitative analysis of Rotary, ultrasonic and manual techniques to treat proximally flattened root canals. J Appl Oral Sci 2007;15:89-93.

17. Langeland $\mathrm{K}$, Liao KKS, Pascon EA. Work saving devices in endodontics: efficacy of sonic and ultrasonic techniques. J Endod 1985;11:499-510.

18. Baratto-Filho $F$, Carvalho JR, Fariniuk LF, Sousa-Neto MD, Pécora JD, Cruz-Filho AM. Morphometric analysis of the effectiveness of different concentrations of sodium hypochlorite associated with instrumentation for root canal cleaning. Braz Dent J 2004;15:36-40.

19. Balto K, Muller R, Carrington DC, Dobeck J, Stashenko P. Quantification of periradicular bone destruction in mice by micro-computed tomography. J Dent Res 2000;79:35-40.

Received December 14, 2011 Accepted May 6, 2013 